\title{
Seroprevalence of typhus group and spotted fever group Rickettsia exposures on Reunion island
}

\author{
Patrick Gérardin ${ }^{1,2^{*}} \mathbb{B}$, Naël Zemali ${ }^{3+}$, Marie Bactora ${ }^{3 \dagger}$, Guillaume Camuset ${ }^{4}$, Elsa Balleydier ${ }^{5}$, Hervé Pascalis ${ }^{2}$, \\ Vanina Guernier ${ }^{6}$, Corinne Mussard ${ }^{1}$, Antoine Bertolotti ${ }^{1,4}$, Yatrika Koumar ${ }^{4}$, Florence Naze ${ }^{3}$, Sandrine Picot ${ }^{3}$, \\ Laurent Filleul ${ }^{5}$, Frédéric Pages ${ }^{5 \neq}$, Pablo Tortosa $^{2 \ddagger}$ and Julien Jaubert ${ }^{3}$
}

\begin{abstract}
Objective: Murine typhus has been increasingly reported on Reunion island, Indian ocean, following documentation of eight autochthonous infections in 2012-2013. We conducted a serosurvey to assess the magnitude of the seroprevalence of rickettsioses in the population. Two hundred and forty-one stored frozen sera taken from the 2009 Copanflu-RUN cohort were analysed using an immunofluorescence assay allowing to distinguish typhus group (TGR) and spotted fever group Rickesttsiae (SFGR). Seropositivity was defined for a dilution titre of Rickettsia IgG antibodies $\geq 1: 64$. Seroprevalence was weighted to account for the discrepancy between the Copanflu-RUN subset and the general population, as to infer prevalence at community level. Prevalence proportion ratios (PPR) were measured using log-binomial models.

Results: The weighted seroprevalences of typhus group rickettsioses and spotted fever group rickettsioses were of $12.71 \%(95 \% \mathrm{Cl} 8.84-16.58 \%)$ and $17.68 \%$ (95\% Cl 13.25-22.11\%), respectively. Pooled together, data suggested that a fifth of the population had been exposed at least to one Rickettsia group. Youths ( $<20$ years) were less likely seropositive than adults (adjusted PPR $0.13,95 \% \mathrm{Cl} 0.01-0.91$ ). People living in the western dryer part of the island were more exposed (adjusted PPR 2.53, 95\% Cl 1.07-5.97). Rickettsioses are endemic on Reunion island and circulated before their first identification as murine typhus in year 2011. Surprisingly, since isolation of Rickettsia africae from Amblyomma variegatum in year 2004 or isolation of Rickettsia felis from Amblyomma loculosum, no autochthonous cases of African tick-bite fever or flea-borne spotted fever has yet been diagnosed.
\end{abstract}

Keywords: Serology, Immunofluorescence, Seroepidemiologic study, Serosurvey, Stored frozen serum, Murine typhus, Spotted fever, Zoonosis, Prevalence, General population

\section{Introduction}

Rickettsiae are Gram negative obligate intracellular bacteria that include several zoonotic pathogens distributed worldwide [1]. The Rickettsia genus is divided phylogenetically into four distinct groups [2].

*Correspondence: patrick.gerardin@chu-reunion.fr

${ }^{\dagger}$ Naël Zemali and Marie Bactora contributed equally to this work

†Frédéric Pages and Pablo Tortosa contributed equally to this work

1 INSERM Centre d'Investigation Clinique 1410 Epidémiologie Clinique,

Centre Hospitalier Universitaire (CHU), Groupe Hospitalier Sud Réunion,

BP 350, 97448 Saint Pierre Cedex, Reunion, France

Full list of author information is available at the end of the article
Typhus group Rickettsiae (TGR) consist of $R$. prowaze$k i i$ and $R$. typhi, the agents responsible for epidemic and murine typhus, respectively. Rickettsia typhi is usually maintained in rodents and transmitted by the rat flea Xenopsylla cheopis [1]. Invasive rodents, specifically the black rats (Rattus rattus), and the brown rats (Rattus norvegicus), serve as primary reservoirs. Humans are infected through contamination of disrupted skin, respiratory tract, or conjunctivae with infected flea faeces. Symptoms are non-specific and cover a large spectrum from mild to severe illness. Even though TGR pathogens are ubiquitous, their burden is higher in tropical regions [3]. 
Spotted Fever Group Rickettsiae (SFGR) encompass 20 Rickettsia species ( $R$. rickettsii, $R$. conorii, $R$. africae, etc....) mostly transmitted by ticks (Dermacentor spp., Amblyomma cajennense and Rhipicephalus sanguineus, etc....) [2]. SFGR multiply in endothelia of almost all organs causing vasculitis. SFGR infections may result into mild to severe and potentially fatal disease.

The ancestral group consists of $R$. canadensis and $R$. bellii, and the transitional group is composed of $R$. akari, $R$. australis and now R. felis (formerly classified in SFGR). Among these, only the transitional group is pathogenic to humans [2].

After a reporting of eight autochthonous cases of TGR infection on Reunion island between January 2011 and January 2013 and a subsequent case series [4, 5], we conducted a serosurvey using stored frozen human sera dated 2009 to assess the magnitude of exposure to Rickettsiae in the community.

\section{Main text \\ Methods \\ Setting and population}

La Réunion is a small tropical island $\left(2512 \mathrm{~km}^{2}\right)$, located in the South Western Indian ocean, $700 \mathrm{~km}$ east of Madagascar. Its landscape gives rise to contrasted climates with a mountainous centre separating a humid windward east coast from a dry leeward west coast. The lower portion of this latter consists of a savannah where introduced rodents ( $R$. rattus and $R$. norvegicus) display distinctly higher flea infestation than in the humid portions of the island [6]. Most of the 816,000 inhabitants present in 2009 lived in the coastal area where the cities lie. The structure by age, gender, and microregion (i.e., 4 administrative regional subdivisions) of the general population is presented in Additional file 1: Table S1.

The study population was a subset of the CoPanFluRUN cohort, dedicated to 2009 pandemic flu [7]. Data pertaining to age, gender, and place of residence were retrieved for each individual and compared to the general population (Additional file 1: Table S1).

\section{Serology}

Two hundred and forty-one sera were tested using an indirect fluorescent antibody (IFA) assay with commercially available $R$. typhi and $R$. rickettsii antigens (IF0100G, Rickettsia IFA IgG ${ }^{\circledR}$, Focus Diagnostics Inc., Cypress, CA, USA) used as TGR and SFGR antigens [8]. A positive specimen with an IgG titre $\geq 1: 64$ was considered as indicative of a previous infection. Each positive sample was further diluted to 1:128 for a more stringent definition. The sera were checked for Coxiella burnetii [9], another Gram negative obligate bacterium, formerly classified within the Rickettsiaceae family and now assigned to the Coxiellaceae.

\section{Statistical analysis}

Statistical analysis was performed using Stata $14.2^{\circledR}$ (StataCorp, College Station; Texas, USA). The seroprevalence rate was measured as crude (raw or unadjusted) and weighted to account for the disproportions between the CoPanFlu-RUN subset and the general population. Associations between positive specimens for TGR or SGR and age, gender and geographic subdivision were determined using weighted Chi square tests. Surveyadjusted log-binomial regression models were used to estimate prevalence proportion ratios (PPR) and 95\% confidence intervals $(95 \% \mathrm{CI})$. A $P$ value $<0.05$ was considered significant.

\section{Results}

The raw seroprevalence of TGR infections at a cut-off of $1: 64$ was of $16.18 \%(39 / 241)$ and the weighted seroprevalence of $12.71 \%$ ( $95 \%$ CI 8.84-16.58\%). These figures were respectively of $9.13 \%(22 / 241)$ and $8.24 \%$ (95\% CI $5.04-$ $11.43 \%$ ) with the more stringent dilution of 1:128.

In comparison, the raw seroprevalence of SFGR infections at a cut-off of 1:64 was of $18.67 \%(45 / 241)$ and the weighted seroprevalence of $17.68 \%$ (95\% CI $13.25-$ $22.11 \%)$. These figures were respectively of $12.86 \%$ (31/241) and $10.44 \%$ (95\% CI 6.89-13.99\%) at a dilution of 1:128.

Altogether, these data revealed that a fifth of the population of Reunion island exhibited a positive serology [22.41\% (54/241); 18.15\%; 95\% CI 13.67-22.63\%], indicative of a previous infection or exposure with either one of the two Rickettsiae groups.

Both TGR and SFGR infections were less frequent among youths $(<20$ years $)$ than among adults, although prevalence did not progress with age through adulthood (Table 1 and Additional file 1: Table S2, Table 2 and Additional file 1: Table S3). Women and men were similarly exposed. The population living in the western dryer microregion was respectively twofold and threefold more likely to have been exposed to TGR and SFGR than people living in the South.

At the cut-off value of 1:64, 30 out of the 54 positive sera $(55.5 \%)$ were positive both to TGR and SFGR. Seven positive sera (13.0\%) also reacted with C. burnetii (2 with both TGR and SFGR, 3 with SFGR alone, 2 with TGR alone).

\section{Discussion}

Rickettsiae are widely distributed in tropical areas and have been previously reported in seabird ticks, rodent 
Table 1 Factors independently associated with typhus group Rickettsiae (TGR) seropositivity in multivariate analysis, Reunion island, $2009(n=241)$

\begin{tabular}{|c|c|c|c|c|}
\hline \multicolumn{5}{|c|}{ Rickettsia typhi lgG $\geq 1: 64$} \\
\hline Variables & $n$ & $\%$ & Adjusted PPR & $95 \% \mathrm{Cl}$ \\
\hline \multicolumn{5}{|l|}{ Age } \\
\hline$<20$ years & $1 / 24$ & 2.07 & $0.13^{*}$ & $0.01-0.9$ \\
\hline 20-39 years & $14 / 77$ & 16.35 & 1 & - \\
\hline 40-59 years & $19 / 102$ & 13.44 & 0.81 & $0.40-1.64$ \\
\hline$\geq 60$ years & $5 / 38$ & 10.28 & 0.51 & $0.18-1.42$ \\
\hline \multicolumn{5}{|l|}{ Gender } \\
\hline Female & $19 / 136$ & 11.69 & 0.74 & $0.40-1.35$ \\
\hline Male & $20 / 105$ & 17.19 & 1 & - \\
\hline \multicolumn{5}{|l|}{ Microregion** } \\
\hline North & $0 / 17$ & 0.00 & NA & - \\
\hline South & $8 / 80$ & 6.76 & 1 & - \\
\hline West & $20 / 78$ & 23.22 & $2.53^{*}$ & $1.07-5.97$ \\
\hline East & $11 / 66$ & 17.74 & 2.21 & $0.85-5.70$ \\
\hline \multicolumn{5}{|c|}{$\begin{array}{l}\text { Data are numbers }(n) \text {, weighted seropositive rates }(\%) \text {, adjusted prevalence } \\
\text { proportion ratios (PPR), and } 95 \% \text { confidence intervals }(95 \% \mathrm{Cl})\end{array}$} \\
\hline \multicolumn{5}{|l|}{ NA not assessed } \\
\hline \multicolumn{5}{|c|}{$\begin{array}{l}P \text { values linked to variable names are given for overall design-based Pearson } \\
\text { chi2 tests }\end{array}$} \\
\hline \multicolumn{5}{|c|}{$P$ values linked to PPR are given for within-each-category Wald tests } \\
\hline \multicolumn{5}{|l|}{${ }^{*} P<0.05$} \\
\hline ** $P<0.01$ & & & & \\
\hline
\end{tabular}

ticks and rodent fleas including on Reunion island [10-12].

Herein, we provide the first serological evidence of a high magnitude exposure of the population living on Reunion island to pathogenic Rickettsiae.

Given our serosurvey was conducted on sera sampled nearly 2 years before the clinical identification of the first autochthonous cases and that the youngest subjects were relatively spared, we suggest that the TGR and SFGR antibodies are long-lived and rickettsioses have been endemic on Reunion island, as previously hypothesized for the Amazon Basin of Peru [13]. Together, these elements support the idea that Rickettsia infections are unrecognized or misdiagnosed and account for a substantial proportion of fevers of unknown origin, as suggested by a case report of prior murine typhus infection in a traveller returning from Reunion island [14].

Another point to highlight is that seropositive subjects live predominantly on the western dryer part of the island, which is both coherent with the spatial distributions of rat fleas and clinical cases $[4,5]$. Furthermore, Rickettsiae from different groups (R. typhi and $R$. felis) have been identified in rat fleas in this part of the island [12]. Importantly, R. africae has been isolated from Amblyomma loculosum, a seabird tick in remote areas
Table 2 Factors independently associated with spotted fever group Rickettsiae (SFGR) seropositivity in multivariate analysis, Reunion island, $2009(n=241)$

\begin{tabular}{|c|c|c|c|c|}
\hline \multicolumn{5}{|c|}{ Rickettsia rickettsii lgG $\geq 1: 64$} \\
\hline Variables & $\mathrm{n}$ & $\%$ & Adjusted PPR & $95 \% \mathrm{Cl}$ \\
\hline \multicolumn{5}{|l|}{ Age } \\
\hline$<20$ years & $0 / 24$ & 0.00 & $N A^{* *}$ & \\
\hline 20-39 years & $13 / 77$ & 18.84 & 1 & - \\
\hline $40-59$ years & $23 / 102$ & 21.88 & 1.22 & $0.55-2.69$ \\
\hline$\geq 60$ years & $9 / 38$ & 21.91 & 1.20 & $0.46-3.15$ \\
\hline \multicolumn{5}{|l|}{ Gender } \\
\hline Female & $25 / 136$ & 17.92 & 1.05 & $0.61-1.82$ \\
\hline Male & $20 / 105$ & 16.61 & 1 & \\
\hline \multicolumn{5}{|l|}{ Microregion } \\
\hline North & $2 / 17$ & 14.63 & 1.62 & $0.30-8.72$ \\
\hline South & $6 / 80$ & 5.73 & 1 & - \\
\hline West & $26 / 78$ & 30.07 & $3.61^{*}$ & $1.32-9.87$ \\
\hline East & $11 / 66$ & 17.01 & 2.10 & $0.68-6.42$ \\
\hline
\end{tabular}

Data are numbers $(\mathrm{n})$, weighted seropositive rates $(\%)$, adjusted prevalence proportion ratios (PPR), and $95 \%$ confidence intervals $(95 \% \mathrm{Cl})$

NA not assessed

$P$ values linked to variable names are given for overall design-based Pearson chi2 tests

$P$ values linked to PPR are given for within-each-category Wald tests

* $P<0.05$

**P $P<0.01$

from human dwellings [11], and its main vector Amblyomma variegatum, a cattle tick, has drastically decreased in the western savannah over the last 20 years [15], which makes unlikely the spill over of $R$. africae from both seabirds or cattle to humans. So, we suggest that $R$. felis may be partially responsible of SFGR seropositivity on Reunion island. Interestingly, $R$. felis, a pathogen that share common features of both SFGR and TGR, has recently been identified in Anopheles gambiae mosquitoes and other non-hematophagous arthropods, which makes the understanding of its transmission pathways very complex with several potential vectors [16]. Another possibility is that a slight proportion of SFGR positive serologies may have been acquired while travelling abroad given the western population is also putatively the most mobile on the island. Consistent with this latter hypothesis, SFGR are endemic in the south western Indian ocean region, where both African tick-bite fever, spotted fever and fleaborne spotted fever regularly diagnosed $[17,18]$.

Finally, our findings warrant a larger scale seroepidemiologic study aimed at better assessing the prevalence of exposure to Rickettsiae and understanding the transmission pathways of these environmental microbial pathogens. Of note, flea indices reported in rodents from the western portion of the island are heterogeneous 
geographically, and fleas were found only in rats from the dry savannah at a low altitude. Hence, a better powered size study should better discriminate into the habitats and provide a finer resolution of the current epidemiological pattern.

\section{Limitations}

This study has potential limitations. First, our findings may be prone to resampling bias given the serosurvey is based on stored frozen sera issued from participants sampled for another purpose. Second, serology cross reactions within the Rickettsiaceae family and with Coxiella burnetii may have precluded the precise identification of the involved pathogens [9]. These things being said, cross reactions with $C$. burnetii were infrequent (13.0\%), so we believe that this limitation is unlikely to change the overall magnitude of Reunion island population exposure to Rickettsiae. Third, it is worth noting that autochthonous clinical cases of spotted fever have never been reported on Reunion island, and within the Rickettsia genus, misclassification may have affected the seroprevalence estimates, given both the likelihood of intra-genus cross reactions and the impossibility to link SFGR antibodies to $R$. felis exposure in our retrospective study.

Notwithstanding, it would be informative to carry out a more specific serosurvey (such as sero-neutralization) in order to identify the pathogens at the species level.

\section{Additional file}

Additional file 1: Table S1. Socio-demographic characteristics of the study population and Réunion island population, 2009. Data are numbers and percentages related to age, gender and residence at both the study population and the community. Table S2. Factors associated with typhus group Rickettssiae (TGR) seropositivity in bivariate analysis, Reunion island, 2009. Table S3. Factors associated with Spotted Fever Group Rickettsiae (SFGR) seropositivity in bivariate analysis, Reunion island, 2009. For Tables S2 and S3, data are numbers, weighted seropositive rates, crude prevalence proportion ratios, and $95 \%$ confidence intervals.

\section{Abbreviations}

CPP: Comité de Protection des Personnes; IFA: indirect fluorescent antibody (alternatively taken as immunofluorescent assay); IgG: immunoglobulin G; $95 \%$ Cl: 95\% confidence interval; PPR: prevalence proportion ratio; SFGR: spotted fever Group Rickettsiae; TGR: typhus group Rickettsiae.

\section{Acknowledgements}

The contributors are indebted to Professor Koussay Dellagi and Doctor François Favier for conducting the CoPanFlu-RUN program. They acknowledge all the members of the CIC-EC de la Réunion, our beloved and regretted friend Doctor Alain Michault, and the researchers of the CRVOI.

\section{Authors' contributions}

$P G, J J$ and $E B$, conceived and designed the experiments. HP, VG, and PT provided the stored frozen sera from the CoPanFlu-RUN biobank. JJ, FN, SP, CM performed the experiments including serological assays. PG and JJ analysed the data with the help of GC, EB, AB, YK, LF, and FP. MB and ZN wrote the initial draft and revised the manuscript, which was extensively reviewed and approved by all the authors. All authors agreed to be personally accountable for the author's own contributions and listed as abovementioned. All authors read and approved the final manuscript.

\section{Funding}

The CoPanFlu-RUN program was supported by funds from CPER-ERDF (Contrat Programme Etat/Region and European Regional Development Fund), INSERM/IMMI and CRVOI. The funder of the CoPanFlu-RUN program did not participate in the design, preparation, data analysis, or decision to publish the manuscript.

\section{Availability of data and materials}

The dataset is available from the corresponding author on reasonable request.

\section{Ethics approval and consent to participate}

The CoPanFlu-RUN protocol was funded by the French National Institute of Health and Medical Research (INSERM). It was conducted in accordance with the Declaration of Helsinki and the French law for biomedical research ( $\mathrm{Nu}$ ID RCBAFSSAPS: 2009-A00689-48). It was approved by the Ethic Committee of Bordeaux 2 University and allowed the re-use of serum samples for the investigation of other infectious diseases.

\section{Consent to publish}

Written informed consent was obtained from all the participants or from the legal representative of all underage participants at the time of CoPanFlu-RUN cohort enrolment. This specified the re-utilisation of the data including for the publication of this report.

\section{Competing interests}

The authors declare that they have no competing interests.

\section{Author details}

${ }^{1}$ INSERM Centre d'Investigation Clinique 1410 Epidémiologie Clinique, Centre Hospitalier Universitaire (CHU), Groupe Hospitalier Sud Réunion, BP 350, 97448 Saint Pierre Cedex, Reunion, France. ${ }^{2}$ UM 134 PIMIT Processus Infectieux en Milieu Insulaire Tropical, INSERM 1187, CNRS 9192, IRD 249, CYROI, Université de La Réunion, Sainte Clotilde, Reunion, France. ${ }^{3}$ Laboratoire de Bactériologie, Virologie et Parasitologie, CHU de la Réunion, Saint Pierre, Reunion, France. ${ }^{4}$ Service des Maladies Infectieuses, CHU de la Réunion, Saint Pierre, Reunion, France. ${ }^{5}$ Cellule d'Intervention Régionale et d'Epidémiologie, Océan Indien, Santé Publique France, French National Public Health Agency, Saint Denis, Reunion, France. ${ }^{6}$ Geelong Centre for Emerging Infectious Diseases, Deakin University, Geelong, VIC, Australia.

Received: 6 April 2019 Accepted: 29 June 2019

Published online: 09 July 2019

\section{References}

1. Raoult D, Roux V. Rickettsioses as paradigms of new or emerging infectious diseases. Clin Microbiol Rev. 1997;10:694-719.

2. Wood H, Artsob H. Spotted fever Group Rickettsiae: a brief review and a Canadian perspective. Zoonoses Public Health. 2012;59:S65-79.

3. Parola P, Raoult D. Tropical rickettsioses. Clin Dermatol. 2006;24:191-200.

4. Balleydier E, Camuset G, Socolovschi C, Moiton MP, Kuli B, Foucher A, et al. Murine typhus, Reunion, France, 2011-2013. Emerg Infect Dis. 2015;21:316-9.

5. Grouteau G, Lancelot O, Bertolotti A, Poubeau P, Manaquin R, Foucher $\mathrm{A}$, et al. Le typhus murin à l'île de La Réunion, caractéristiques cliniques, biologiques et épidémiologiques. Ann Dermatol Venereol. 2017;144(Suppl 2):S287. https://doi.org/10.1016/j.annder.2017.09.475.

6. Guernier V, Lagadec E, LeMinter G, Licciardi S, Balleydier E, Pagès F, et al. Fleas of small mammals on Reunion Island: diversity, distribution and epidemiological consequences. PLoS Negl Trop Dis. 2014;8:e3129.

7. Dellagi K, Rollot O, Temmam S, et al. Pandemic influenza due to pH1N1/2009 virus: estimation of infection burden in Reunion Island through a prospective serosurvey, austral winter 2009. PLoS ONE. 2011;6:e25738. 
8. Kantsø B, Svendsen CB, Jørgensen CS, Krogfelt KA. Evaluation of serological tests for the diagnosis of rickettsiosis in Denmark. J Microbiol Methods. 2009;76:285-8.

9. Jaubert J, Naze F, Camuset G, Larrieu S, Pascalis H, Guernier V, et al. Seroprevalence of Coxiella burnetii (Q fever) exposure in humans on Reunion Island. Open Forum Infect Dis. 2009. https://doi.org/10.1093/ofid/ofz227 (in press).

10. Parola P, Barre N. Rickettsia africae, agent de la fièvre à tique africaine: un pathogène émergent dans les Antilles et I'lle de La Réunion. Bull Soc Pathol Exot. 2004;97:193-8.

11. Dietrich M, Lebarbenchon C, Jaeger A, Le Rouzic C, Bastien M, Lagadec E, et al. Rickettsia spp. in seabird ticks from western Indian ocean islands, 2011-2012. Emerg Infect Dis. 2014;20:838-42.

12. Dieme C, Parola P, Guernier V, Lagadec E, LeMinter G, Balleydier E, et al. Rickettsia and Bartonella species in fleas from Reunion Island. Am J Trop Med Hyg. 2015;92:617-9.

13. Forshey BM, Stewart A, Morrison EM, Galvez H, Rocha C, Astete $H$, et al. Epidemiology of spotted fever group and typhus group rickettsial infections in the Amazon basin of Peru. Am J Trop Med Hyg. 2010;82:683-90.

14. Walter G, Botelho-Nevers E, Socolovschi C, Raoult D, Parola P. Murine typhus in returned travelers: a report of thirty-two cases. Am J Trop Med Hyg. 2012;86:1049-53.
15. Stachurski F, Tortosa P, Rahajarison P, Jacquet S, Yssouf A, Hubert K. New data regarding distribution of cattle ticks in the south-western Indian Ocean islands. Vet Res. 2013;44:79.

16. Angelakis E, Mediannikov O, Parola P, Raoult D. Rickettsia felis: the complex journey of an emergent human pathogen. Trends Parasitol. 2016;32:554-64.

17. Rakotonanahary RJ, Harrison A, Maina AN, Jiang J, Richards AL, Rajerison $\mathrm{M}$, et al. Molecular and serological evidence of flea-associated typhus group and spotted fever group rickettsial infections in Madagascar. Parasit Vectors. 2017;10:125

18. Albízuri Prado F, Sánchez A, Feito M, Mayor A, Rodriguez A, de Lucas R. Fever and multiple eschars after an African safari: report of three cases. Pediatr Dermatol. 2017;34:e179-81.

\section{Publisher's Note}

Springer Nature remains neutral with regard to jurisdictional claims in published maps and institutional affiliations.
Ready to submit your research? Choose BMC and benefit from:

- fast, convenient online submission

- thorough peer review by experienced researchers in your field

- rapid publication on acceptance

- support for research data, including large and complex data types

- gold Open Access which fosters wider collaboration and increased citations

- maximum visibility for your research: over $100 \mathrm{M}$ website views per year

At BMC, research is always in progress.

Learn more biomedcentral.com/submissions 